\title{
Free-Volume Formation and Relaxation in a Poly(ethylene oxide)/Poly(methyl methacrylate) Blend II. Structural Relaxation and Volume Change
}

\author{
Shigetaka SHImADA ${ }^{\dagger}$ and Osamu IsoGaI
}

Nagoya Institute of Technology, Gokiso-cho, Showa-ku, Nagoya 466, Japan

(Received October 25, 1995)

\begin{abstract}
The electron spin resonance (ESR) line shape of nitroxide radical labels attached to poly(ethylene oxide) (PEO) chains in a blend with isotactic poly(methyl methacrylate) (PMMA) of higher molecular weight than that in Part I of this series was studied as a function of aging and annealing temperatures. Two spectral components with different rates of motion, a "fast" component and a "slow" component arising from the radicals, are also observed. The fractional amount of the fast component (mobile fraction) observed at $27^{\circ} \mathrm{C}$ changes with aging and annealing temperatures. The fraction decreases abruptly around $-15^{\circ} \mathrm{C}$ with decreasing aging temperature, whereas the fraction increases abruptly around $50^{\circ} \mathrm{C}$ with increasing annealing temperature. The specific volume of the blend was measured at $27^{\circ} \mathrm{C}$ by the dilatometric method. ca. $0.5 \%$ of volume contraction and expansion during aging at $-15^{\circ} \mathrm{C}$ and annealing at $50^{\circ} \mathrm{C}$, respectively were observed, attributed to relaxation related to free-volume formation and relaxation in an amorphous region of the blend.

KEY WORDS Electron Spin Resonance / Spin Label / Dilatometer / Differential Scanning Calorimetry / Phase Separation / Molecular Mixing / Molecular Motion / Free Volume / Volume Relaxation
\end{abstract}

Many authors have studied polymer blends extensively by a variety of methods. ${ }^{1}$ It is very important that microscopic properties are related to macroscopic quantities such as volume, ${ }^{2}$ enthalpy, ${ }^{3}$ or mechanical properties, and stress relaxation. ${ }^{4}$ For example, negative or excess volume for mixing ${ }^{5,6}$ is a very important factor in the miscibility and phase behavior of polymer blend. Structural changes induced by interactions between the components may be the origin of volume change. Studies of the microscopic free-volume properties of molecular and atomic scales provide a basic understanding of the mechanical and physical properties of polymers. In recent years, a new micro analytical probe, positron annihilation spectroscopy ${ }^{7}$ has been developed to probe free-volume hole properties in polymer materials. Some authors have studied free-volume distribution and physical aging in a glassy polymer by using photochromic fluorescent and spin probes. ${ }^{8}$ The dynamic properties of polymer materials should depend on the density of molecular packing, i.e., on free-volume..$^{9-12}$ We developed spin-label techniques to investigate the structures and the dynamic behavior of polymer chains at a particular site in a complicated system. ${ }^{13}$

Previously, we found that an electron spin resonance (ESR) spectra of the nitroxide label reflect different environments in a poly(ethylene oxide) (PEO)/poly(methyl methacrylate) (PMMA) blend, with different motional characteristics ${ }^{14,15}$; two spectral components with different rates of motion, "fast" and "slow" components, are observed, with isotropic spectra reflecting fast motion and anisotropic spectra immobilized labels. We also estimated the fractional amount of the fast component (mobile fraction) of the composite spectra observed at room temperature and studied the effects of physical aging on the mobile fraction. The fractions dropped around $-13^{\circ} \mathrm{C}$ and the mobile labels appeared abruptly at $60^{\circ} \mathrm{C}$. These characteristic changes could be interpreted as due to free-volume formation and relaxa- tion in the PEO-rich phase of a phase-separated system.

This motivated us to consider macroscopic volume change attending the relaxation. Here, we estimate the volume of a polymer blend observed at room temperature by dilatometer and study the effects of physical aging on volume. A comparison of the volume change with variation of the mobile fraction of the composite ESR spectra should clarify relaxation in an amorphous region of the polymer blend. Another aim of this study is to elucidate the molecular weight dependence of freevolume formation and relaxation. Then, we use isotactic PMMA which has 60 times higher molecular weight than the sample used in part I of this series. ${ }^{16}$

\section{EXPERIMENTAL}

\section{Materials}

The preparation of spin-labeled $\mathrm{PEO}^{17}$ was described in detail in our previous papers. ${ }^{14,15}$ Isotactic PMMA was purchased from Aldrich Chemical Co., Ltd. The number average molecular weight $\left(\bar{M}_{n}\right)$ is $6 \times 10^{3}$ for PEO and $3.2 \times 10^{5}$ for PMMA. The non spin-labeled PEO was used for measurement of differential scanning calorimeter (DSC) and dilatometer.

\section{Preparation of Blends}

Blends were made by mixing PEO and PMMA at ratios of $1: 1$ and $1: 10$ by weight. Films were prepared by casting from $\sim 3 \mathrm{wt} \%$ of benzene solution at $60^{\circ} \mathrm{C}$. The sample codes used for these samples are EMH1 and EMH10.

\section{ESR Measurements}

Samples were stacked in ESR sample tubes and evacuated to $10^{-5} \mathrm{mmHg}$. ESR measurements were carried out with a JEOL FE3XG spectrometer with a PC9801 computer. The magnetic field sweep was calibrated with the known splitting constant of $\mathrm{Mn}^{2+}$.

\footnotetext{
† To whom correspondence should be addressed.
} 


\section{Dilatometry}

$1.0 \mathrm{~g}$ of dry sample was placed in a dilatometer composed of a capillary with homogeneous inner diameter, which was evacuated and filled with mercury at room temperature. The dilatometer was placed in an oil bath at $27^{\circ} \mathrm{C}$ and the meniscus height of mercury inserted in the capillary of the dilatometer was measured using a precise cathetometer. To study the effects of annealing on the volume, specific volume was observed at $27^{\circ} \mathrm{C}$ after the annealing at various temperatures for $30 \mathrm{~min}$.

\section{DSC Measurements}

DSC measurements were carried out using a Rigaku HF-2 differential scanning calorimeter. DSC scans were run from $-100^{\circ} \mathrm{C}$ to $100^{\circ} \mathrm{C}$ at $2^{\circ} \mathrm{C} \mathrm{min}^{-1}$.

\section{RESULTS AND DISCUSSION}

\section{Free-Volume Relaxation Detected by the Spin-Label Method}

Figure 1 shows the ESR spectrum of the spin-labeled $\mathrm{PEO}$ in the EMH10 blend. The spectrum was observed at $27^{\circ} \mathrm{C}$ after the sample was annealed at $91^{\circ} \mathrm{C}$ for 30 min and stored at ambient temperature for a long time (more than 1 week). The blend proceeded to be a phase separated state. In general, the outermost splitting width of the main triplet spectra due to hyperfine coupling caused by the nitrogen nucleus narrows with increasing mobility of the radicals because of motional averaging of anisotropic interactions between electron and nuclear spins. The complete averaging gives rise to an isotropic and narrowed spectrum. The outermost splitting is a good measure of the mobility of the spin-labeled PEO. Two components of spectra in the blend with different rates of motion, "fast" and "slow" components arising from the radicals, are observed. The fast and slow components can be attributed to radicals in the mobile and rigid regions, respectively. Molecular mobility in the PEO matrices is higher than in the PMMA matrices since the glass-rubber transition temperature $\left(T_{\mathrm{g}}\right)$ of PEO $\left(-65^{\circ} \mathrm{C}\right)$ is lower than that of isotactic PMMA $\left(60^{\circ} \mathrm{C}\right) .^{18,19}$ As discussed previously, this means that nitroxide radicals are affected by the environment, for example, aggregation, and the fast and slow component spectra (the isotropic and anisotropic spectra) are attributed to the spin-labeled PEO trapped in the mobile and immobile regions of the blend, respectively. For instance, mobile PEO labels are trapped in the mobile region of the PEO-rich phase and immobile PEO labels are present in the immobile region of the PEO-rich phase and in the PMMA-rich phase. We can deconvolute the experimental spectrum into two components and estimate the fractional amount of the fast component (mobile fraction) as mentioned in our previous paper. ${ }^{15}$ The blend sample was stored at $-39^{\circ} \mathrm{C}$ for $30 \mathrm{~min}$ and subsequently heated to room temperature, and ESR measurement was carried out at the same temperature. The mobile component spectrum disappears and the intensity of the outermost peaks of the slow component indicated as $I$ in Figure 1 increases during aging. The variation of the ESR spectra shown in Figure 1 can be interpreted in terms of a "freezing" of free volume in the $\mathrm{PEO}$-rich region, for instance, free-volume relaxation,

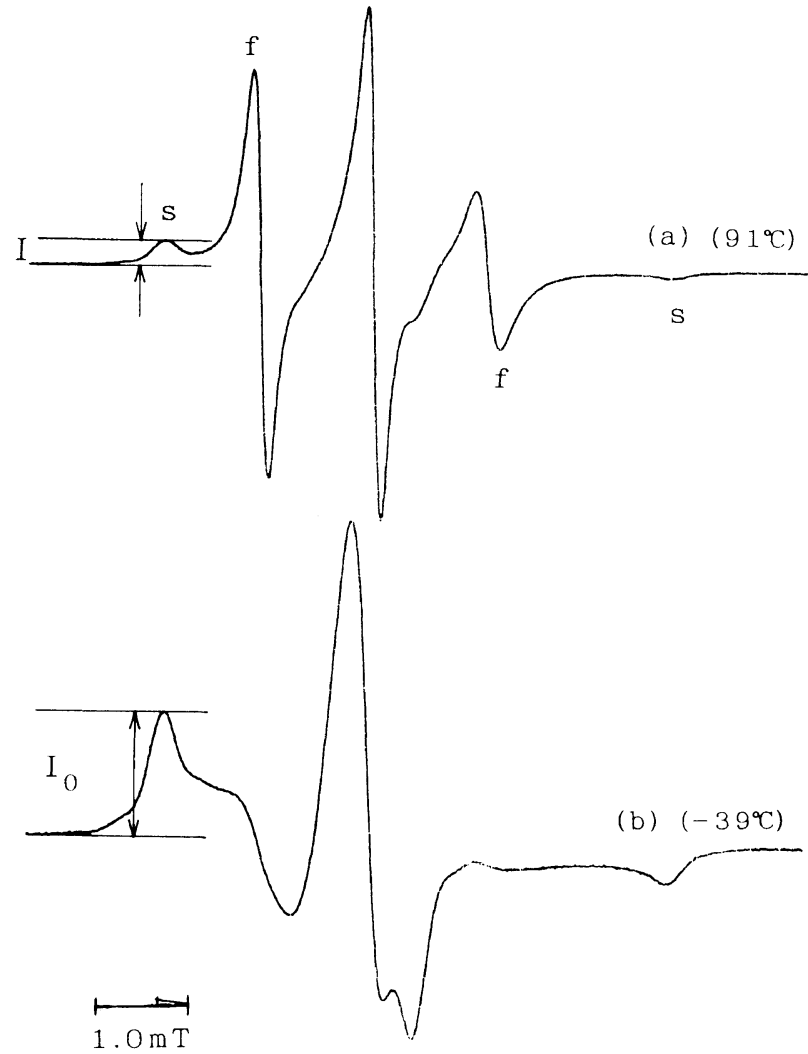

Figure 1. ESR spectra of spin-labeled PEO in PEO/PMMA blend (EMH10) after annealing at $91^{\circ} \mathrm{C}$ for $30 \mathrm{~min}$ (a) and after aging at $-39^{\circ} \mathrm{C}$ for $30 \mathrm{~min}(\mathrm{~b})$. Slow and fast components are indicated by "s" and "f", respectively. Measurements were carried out at $27^{\circ} \mathrm{C}$.

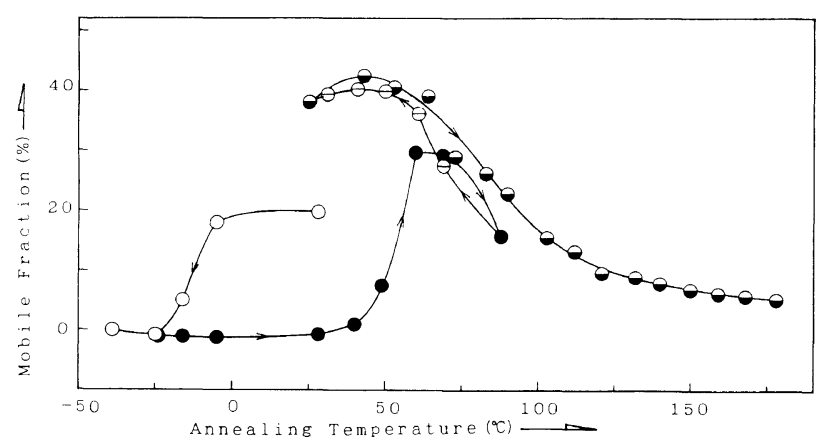

Figure 2. Change in mobile fraction of ESR spectra of spin-labeled PEO in PEO/PMMA blend (EMH10) with aging and annealing temperature. The arrows indicate the routes on which the changes of the mobile fraction were observed. Measurements were carried out at $27^{\circ} \mathrm{C}$. $\bigcirc$, the first cooling; $\bigcirc$, the first heating; $\ominus$, the second cooling; $\ominus$, the second heating.

as discussed in our previous paper. ${ }^{15}$ Mobile fraction should be a good measure of the distribution of free volume. In order to study the effects of physical aging and annealing on the mobile fraction, ESR measurements were carried out at $27^{\circ} \mathrm{C}$ after heat-treatment at various temperatures for $30 \mathrm{~min}$. For simplicity, the mobile fraction is estimated as $\left(I_{0}-I\right) / I_{0}$ from the relative intensity of the outermost peaks of the slow component spectrum to that $\left(I_{0}\right)$ of only one slow component spectrum as shown in Figure 1(b). Figure 2 shows an example of the changes of the mobile fraction with aging and annealing temperatures.

First, the EMH10 blend sample as cast was aged at temperatures lower than $27^{\circ} \mathrm{C}$. The mobile fraction de- 
creases with decreasing aging temperature at $-5^{\circ} \mathrm{C}$ to $-15^{\circ} \mathrm{C}$. This suggests that the volume in the PEO-rich phase of the phase-separated system contracts and spinlabeled PEO becomes immobile. For instance, structural change should involve the free-volume relaxation.

Secondly, the EMH10 sample was annealed at temperatures of $-50^{\circ} \mathrm{C}$ to $60^{\circ} \mathrm{C}$. The mobile fraction increases abruptly around $50^{\circ} \mathrm{C}$. This can be interpreted in terms of volume expansion in the PEO-rich phase. The variation of the mobile fraction with annealing is attributed to free-volume formation. The characteristic temperatures at which the mobile fraction decreased and increased drastically should be related to the glassrubber transition temperatures of PEO $\left(-65^{\circ} \mathrm{C}\right)$ and PMMA $\left(60^{\circ} \mathrm{C}\right)$. The contraction and stretching of PEO and PMMA chains in the blend may play an important role in structural change in the PEO-rich region.

Thirdly, the sample was annealed at temperatures higher than $60^{\circ} \mathrm{C}$. The mobile fraction decreases with increasing annealing temperatures. This should be responsible for molecular mixing of the PEO and PMMA chains and hindrance of the PMMA chains for the motion of the PEO chains, as discussed in part I of this series. ${ }^{16}$ For instance, molecular mobility depends on the density of the molecular packing, free-volume distribution, and intermolecular interaction. The different values of the mobile fraction at $27^{\circ} \mathrm{C}$ before $(\bigcirc)$ and after $(\ominus)$ annealing as shown in Figure 2 indicate that the blend sample as cast is not completely phase separated and approaches equilibrium by annealing at higher temperatures.

The variation of the mobile fraction for the EMH1 sample, as shown in Figure 3 was almost the same as for the EMH10 sample, as shown in Figure 2.

The molecular weight dependence of the mobile fraction $v s$. temperature curve was found. For example, the curve for the higher molecular weight of isotactic PMMA $\left(\bar{M}_{n}=3.2 \times 10^{5}\right)$ as shown in Figure 2 is compared with that for the low molecular weight $\left(\bar{M}_{n}=\right.$ $5 \times 10^{3}$ ) as shown in Figure 3 in Part $\mathrm{I}^{16}$ Increasing the molecular weight gave rise to: (I) The temperature at which the mobile fraction decreases above $27^{\circ} \mathrm{C}$ shifts to higher temperature. (II) The temperature at which the mobile fraction increases after the aging below $-10^{\circ} \mathrm{C}$, becomes $\mathrm{ca} .10^{\circ} \mathrm{C}$ lower. These changes are also observed for blend samples of fractional ratio of $1: 1$. The curve for the EMH1 sample as shown in Figure 3 can be compared with that for the EM1 sample as shown in Figure 4 in part I of this series. ${ }^{16}$

These findings should be responsible for the change of phase diagram of an upper critical solution temperature type concluded for the PEO/isotactic PMMA blend in the previous paper, ${ }^{16}$ with molecular weight of isotactic PMMA. For instance, the phase diagram for the blend of isotactic PMMA $\left(\bar{M}_{n}=3.2 \times 10^{5}\right)$ and PEO $\left(\bar{M}_{n}=6 \times 10^{3}\right)$ is not more symmetric and appears in a higher temperature range than that for the blend of isotactic PMMA of the low molecular weight $\left(\bar{M}_{n}=\right.$ $\left.5 \times 10^{3}\right)$ and PEO of the same molecular weight $\left(\bar{M}_{n}=\right.$ $\left.6 \times 10^{3}\right)$. Therefore, increasing the molecular weight of isotactic PMMA shifts the temperature at which molecular mixing proceeds, to higher temperature and decreases the characteristic temperature of free-volume

Polym. J., Vol. 28, No. 8, 1996

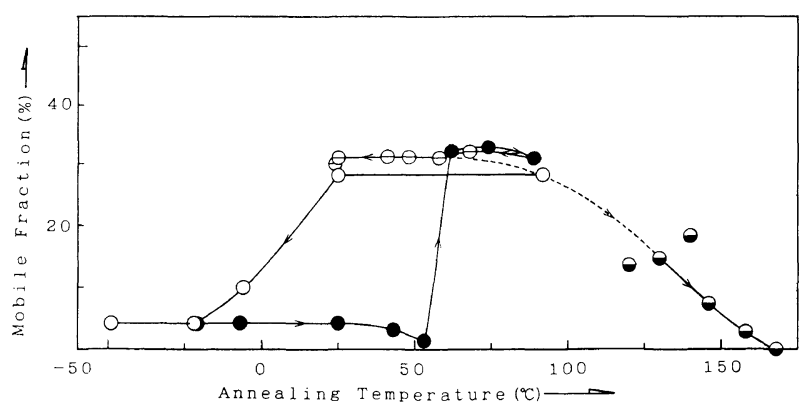

Figure 3. Change in mobile fraction of ESR spectra of spin-labeled PEO in PEO/PMMA blend (EMH1) with aging and annealing temperature. The arrows indicate routes on which changes of the mobile fraction were observed. Measurements were carried out at $27^{\circ} \mathrm{C}$. $\bigcirc$, the first cooling; $\odot$, the first heating; $\ominus$, the second cooling; $\ominus$, the second heating.

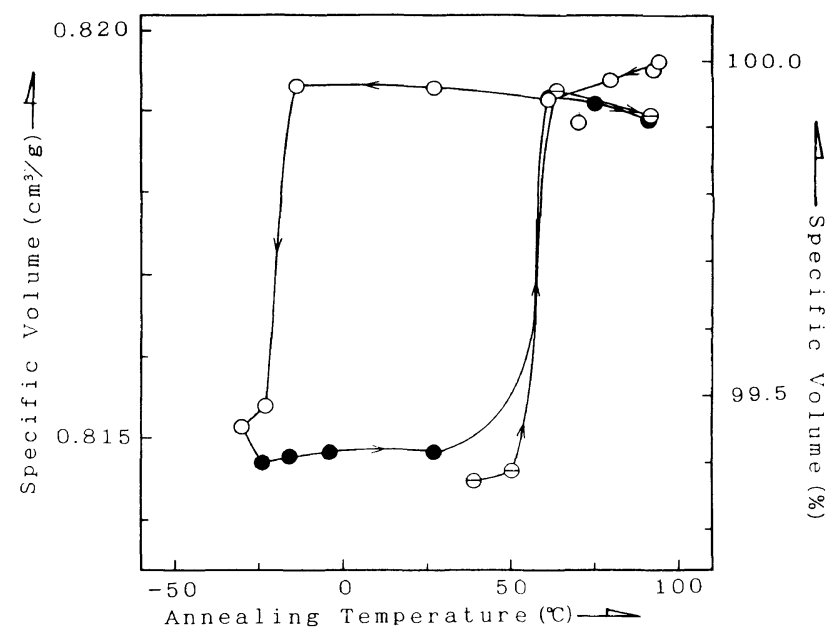

Figure 4. Change in specific volume of PEO/PMMA blend (EMH10) with aging and annealing temperature. The arrows indicate the routes on which the changes of the specific volume were observed. $\bigcirc$, the 1 st cooling; $\bigcirc$, the lst heating; $\ominus$, the 2nd heating. Measurements of specific volume were carried out at $27^{\circ} \mathrm{C}$.

formation because of the lower concentration of PMMA chains in the PEO-rich phase.

\section{Free-Volume Relaxation Detected by the Dilatometric Method}

The PEO spin label is located at the PEO chain end and the spin label may have more dynamic freedom than the intrachain segment and may not reflect the situation in the blend mentioned in the previous section. To confirm the phenomena by other techniques, dilatometric measurement is carried out by the same procedure in the spin-label technique. Figure 4 shows the changes of specific volume observed at $27^{\circ} \mathrm{C}$ with aging and annealing temperatures. The blend sample was stored at a desired temperature for $30 \mathrm{~min}$ and subsequently placed in an oil bath regulated at $27^{\circ} \mathrm{C}$ for more than $30 \mathrm{~min}$. The meniscus height of mercury in the capillary of the dilatometer was measured.

First, the specific volume at $27^{\circ} \mathrm{C}$ was observed with decreasing aging temperature after the sample was annealed at $94^{\circ} \mathrm{C}$ for $30 \mathrm{~min}$ and the same procedures were performed with decreasing temperature of the heat-treatment in a range of $94^{\circ} \mathrm{C}$ to $-30^{\circ} \mathrm{C}$ (Figure $4(\mathrm{O})$. The specific volume drops abruptly at $-14^{\circ} \mathrm{C}$ to 


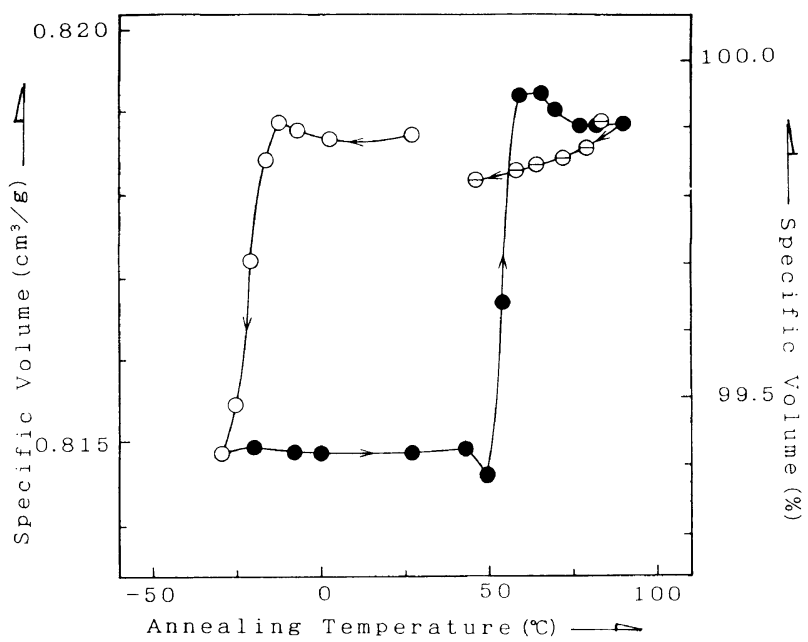

Figure 5. Change in specific volume of PEO/PMMA blend (EMH10) with aging and annealing temperature after the second cycle. The arrows indicate the routes on which the changes of the specific volume were observed. $\bigcirc$, the 3rd cooling; $\bigcirc$, the 3rd heating; $\ominus$, the 4 th cooling. Measurements of specific volume were carried out at $27^{\circ} \mathrm{C}$.

$-23^{\circ} \mathrm{C}$. ca. $0.5 \%$ of volume contracts, i.e., relaxation of free volume sites, occurs. It is mainly noted that the structure developed below $27^{\circ} \mathrm{C}$ is unchanged at the same temperature, $27^{\circ} \mathrm{C}$. The formation of free volume sites, i.e., volume expansion cannot be observed within a few hours at $27^{\circ} \mathrm{C}$, i.e., the relaxation time for the recovery of the structure is too long to observe by the dilatometric method.

Secondly, after aging, the EMH10 sample was annealed at $-30^{\circ} \mathrm{C}$ to $60^{\circ} \mathrm{C}$ (Figure $4(0)$. The specific volume increases abruptly around $50^{\circ} \mathrm{C}$. This can be interpreted in terms of volume expansion. These changes of the macroscopic quantity occur in the just same temperature range as for the mobile fraction estimated by the spin-label method.

To confirm the reproducibility of these experimental results, aging and annealing cycles for the just same sample were carried out repeatedly. After heat-treatment of the first cycle, the sample was aged at $-38^{\circ} \mathrm{C}$ for $30 \mathrm{~min}$ and annealing was continued. The specific volume increases abruptly at $50^{\circ} \mathrm{C}$ as shown in Figure $4(\mathrm{O})$. The experimental results of the third cycle are shown in Figure 5. The aging in a range of $27^{\circ} \mathrm{C}$ to $-30^{\circ} \mathrm{C}(\mathrm{O})$ was performed after the sample was at ambient temperature for a long time (more than 1 week), subsequently the annealing temperature was increased ( $\mathbf{O})$, and finally the temperature was decreased from $90^{\circ} \mathrm{C}$. It is apparent that contraction and expansion of volume around $-15^{\circ} \mathrm{C}$ and $50^{\circ} \mathrm{C}$, respectively, are reversible with respect to aging and annealing temperatures. As shown in Figures 4 and 5, a slight change of volume with annealing temperature higher than $60^{\circ} \mathrm{C}$ was observed. The specific volume also decreases with increasing temperature (O), whereas volume decreases with decreasing temperature $(\Theta)$. The change is irreversible with respect to annealing temperature. These facts may reflect molecular mixing of the PEO and PMMA chains and phase separation, having a non equilibrium character.

Figure 6 shows variation of the specific volume of the EMH1 blend at $27^{\circ} \mathrm{C}$ with aging and annealing 658

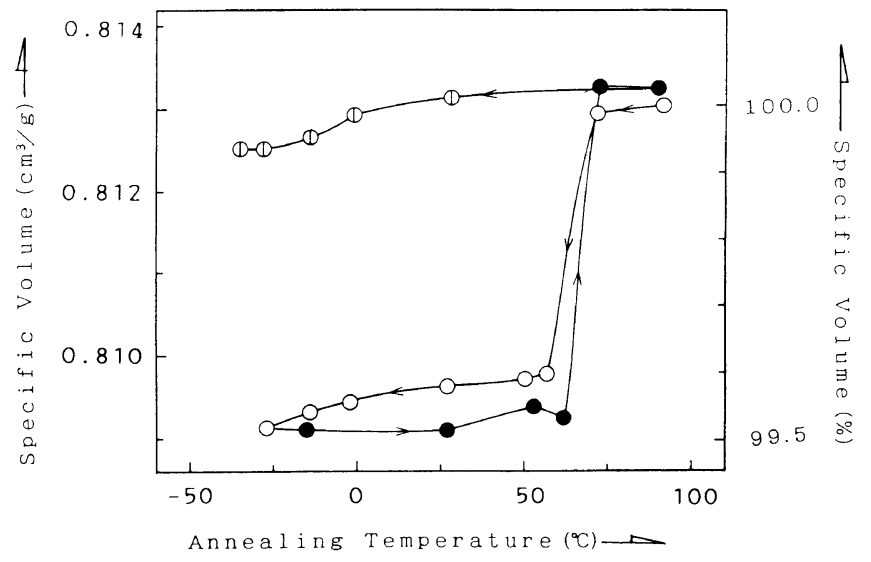

Figure 6. Change in specific volume of PEO/PMMA blend (EMH1) with aging and annealing temperature. The arrows indicate the routes on which the changes of the specific volume were observed. $\bigcirc$, the 1 st cooling; , the 1st heating; (1), the 2nd cooling after the 1st cycle and quenching to room temperature. Measurements of specific volume were carried out at $27^{\circ} \mathrm{C}$.

temperatures. First, the specific volume at $27^{\circ} \mathrm{C}$ was measured after the sample was annealed at $94^{\circ} \mathrm{C}$ for $30 \mathrm{~min}$ and next, the change of the specific volume was observed with decreasing temperature as performed for the EMH10 blend (Figure 6(O)). The remarkable drops in two temperature ranges, $70-55^{\circ} \mathrm{C}$ and $27--20^{\circ} \mathrm{C}$ are found. The volume change, $c a .0 .4 \%$ in the higher temperature range should be caused by partial crystallization of PEO molecules in the blend. On the other hand, the small change of volume, $c a .0 .1 \%$ can be considered to be responsible for free-volume relaxation mentioned above. The volume contraction is 5 times lower than that observed for the EMH10 blend as shown in Figures 4 and 5. The increasing content of PEO in the EMH1 blend in comparison with the EMH10 blend increases the rate of the crystallization of PEO molecules and decreases the content of the amorphous region in the blend. Secondly, the EMH1 blend was annealed at temperatures at $-30^{\circ} \mathrm{C}$ to $90^{\circ} \mathrm{C}$. The specific volume increases abruptly at $c a .65^{\circ} \mathrm{C}$, which coincides with the melting temperature of PEO crystalline, as shown in Figure $6(\mathbf{O})$. The free-volume formation in the amorphous region must be obscured in the increasing of the specific volume, due to melting to the PEO crystalline.

The sample of the EMH1 blend was quenched rapidly to room temperature after heat-treatment of the first cycle. The specific volume was measured with decreasing aging temperatures (Figure 6(O)). Only a small change in temperature of $27^{\circ} \mathrm{C}$ to $-25^{\circ} \mathrm{C}$ was observed. It can be considered that $\mathrm{PEO}$ molecules cannot crystallize for $30 \mathrm{~min}$ and molecular mixed state of the blend is memorized at room temperature.

These expansion and contraction of volume are compatible with the free-volume formation and relaxation detected by the spin label method.

\section{Free-Volume Relaxation in an Amorphous Region}

Contraction and expansion of volume in the PEO/ PMMA blend occurred around $-15^{\circ} \mathrm{C}$ and $50^{\circ} \mathrm{C}$, respectively, by the spin-label and dilatometric methods. Here, we raise two questions: Whether the volume change estimated by dilatometer is attributed to free volume 


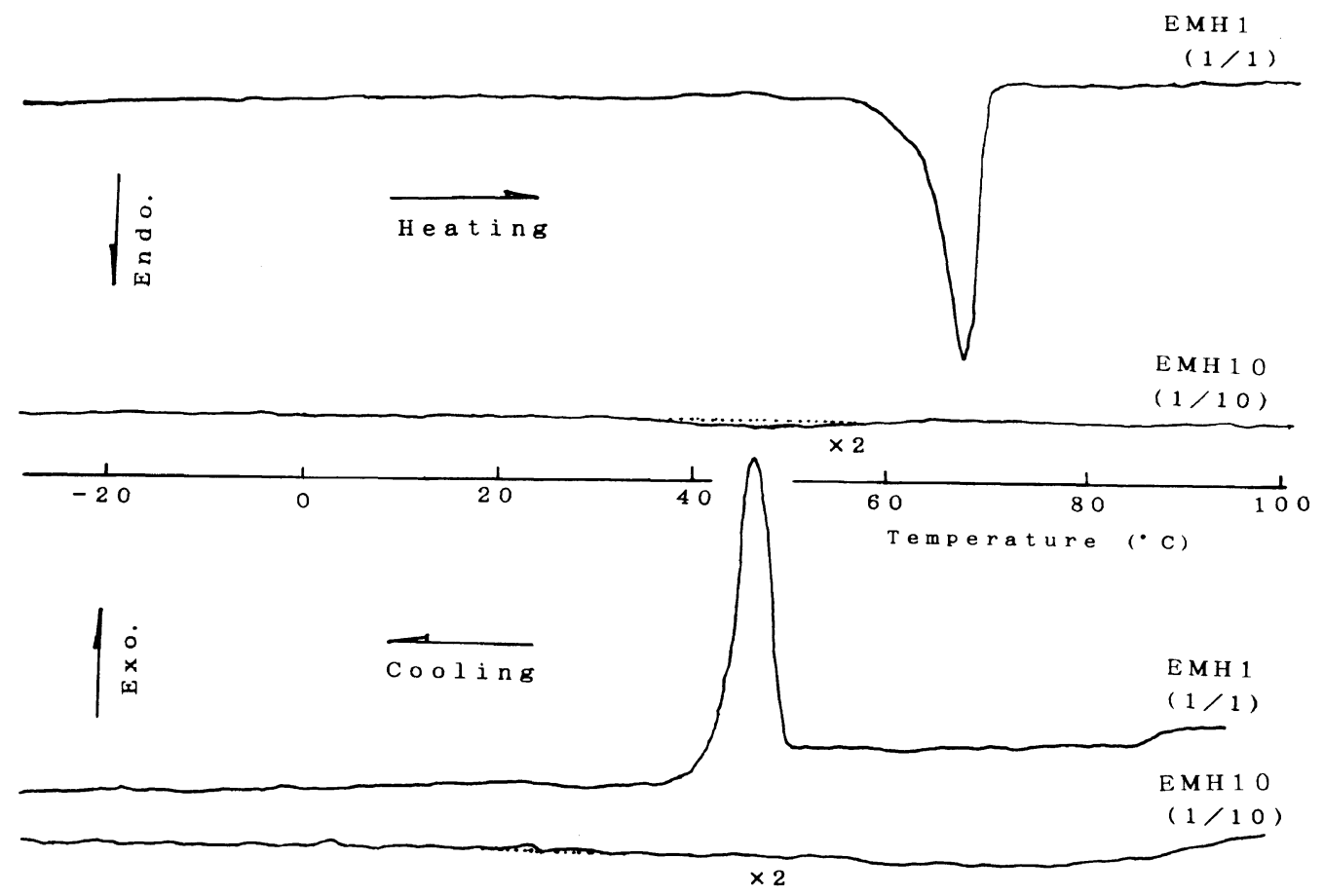

Figure 7. DSC traces of PEO/PMMA blends. Values in parentheses indicate fractional ratios of PEO:PMMA by weight.

relaxation or to crystallization of PEO chain?

Why are the relaxation temperature ranges of the contraction and expansion of volume different?

To answer these questions, one must acquire a knowledge of the crystallinity of PEO, phase structure and molecular mobility in the polymer blend. A large spinlabel cannot penetrate a crystalline region of a polymer, and then the mobile fraction estimated by the ESR method is focused on a particular region: an amorphous region of PEO-rich phase of the phase-separated system. Some authors determined the specific volumes of crystalline $\left(V_{\mathrm{c}}\right)$ and amorphous $\left(V_{\mathrm{a}}\right)$ regions of PEO. ${ }^{20}$ Here, we apply the values of $V_{\mathrm{c}}$ and $V_{\mathrm{a}}$ at $25^{\circ} \mathrm{C}$ as 0.815 and $0.890\left(\mathrm{mlg}^{-1}\right)$, respectively and we calculate a volume change, $7.5 \%$ with melting of all crystals of PEO. In the EMH10 blend of PEO and PMMA having $100 \%$ crystallinity of PEO, the volume change with melting was calculated as $0.68 \%$. In general, the volume change in the blend should be estimated by multiplying the crystallinity by $0.68 \%$. On the other hand, crystallization of PEO chains in polymer blends of PEO/atactic PMMA and PEO/isotactic PMMA has been studied by many authors. ${ }^{18-19,21}$ PMMA chains disturb the crystallization of PEO chains and crystallinity in the polymer blend should be low. Figure 7 shows typical thermograms obtained for the PEO/PMMA blend as cast. There is no enthalpy associated with the melting endotherm of PEO crystalline for the EMH10 blend, whereas some enthalpy is observed for the EMH1 blend. There is also no evident exotherm due to crystallization of PEO chains during the cooling process for the EMH10 blend. After the blend sample of EMH10 was aged at $-20^{\circ} \mathrm{C}$ for $30 \mathrm{~min}$, DSC was carried out. Small enthalpy associated with melting endotherm of the PEO crystalline was observed as $2.8 \mathrm{~J} \mathrm{~g}^{-1}$, and the crystallinity of PEO in the blend can be obtained by taking $190 \mathrm{~J} \mathrm{~g}^{-1},{ }^{22}$ as enthalpy of fusion of $100 \%$ crystalline PEO. The volume change in the blend can be calculated as $c a .0 .1 \%$ less than the volume change, $0.5 \%$ obtained by the dilatometric method. Thus, it is possible to prepare an almost pure, amorphous blend, having a high PMMA content. Therefore, the volume change, $0.5 \%$ in the EM10 blend, estimated by the dilatometric method is not attributed to crystallization of PEO chains and melting of the PEO crystals, but to free-volume relaxation in an amorphous region of the blend.

Molecular mobility is an important factor in the structure of polymer material; for example, rubber elasticity is responsible for a micro Brownian type molecular motion. Characteristic temperatures at which contraction and expansion of free volume in the PEO/ PMMA blend occur should be related to the glass-rubber transition temperatures of PEO and PMMA. The rates of molecular motion of PEO and PMMA chains in the blend are different. ${ }^{21}$ The mobility of the components are estimated using spin-label PEO or spin-labeled PMMA in the same blend. The different rates of molecular motion of the PEO and PMMA chains in the polymer blend should give rise to different relaxation times of the structural developments of contraction and expansion.

Acknowledgments. We are grateful to Prof. Tujita, Dr. Kinosita and Dr. Hori, and Mr. Yamamoto (Nagoya Institute of Technology) for helpful discussion, dilatometric measurements and DSC measurements.

\section{REFERENCES}

1. For example: (a) L. A. Utracki, "Polymer Alloys and Blends," Hanser, New York, N.Y., 1989. (b) M. M. Coleman, J. E. Graf, and P. C. Printer, "Specific Interactions and the Miscibility of Polymer Blend," Technomic, Lancaster, 1991.

2. For example: (a) R. Greiner and F. R. Schwarzyl, Colloid Polym. Sci., 267, 39 (1989). (b) A. J. Hill, I. M. Katz, and P. L. Jones, 
Polym. Eng. Sci., 30, 762 (1990). (c) Y. Tujita, M. Kato, T. Kinosita, and A. Takizawa, Polymer, 33, 773 (1992).

3. For example: (a) G. Brinke and R. Grooten, Colloid Polym. Sci., 267, 992 (1989).

(b) J. M. G. J Cowie and R. Ferguson, Macromolecules, 22, 2307 (1989). (c) B. T. Chang and J. C. M. Li, J. Polym. Sci. Polym. Chem. Ed., 27, 1125 (1989).

4. For example: M. Shmorhun, A. M. Jamieson, and R. Simha, Polymer, 31, 812 (1990).

5. M. Wolf and J. H. Wendorff, Polym. Commun., 31, 226 (1990).

6. M. Wolf and J. H. Wendorff, Polymer, 30, 1524 (1989).

7. Q. Deng and Y. C. Jean, Macromolecules, 26, 30 (1993), and references in therein.

8. For example: (a) L. Lamarre and C. S. P. Sung, Macromolecules, 16, 1729 (1983). (b) I. Mita, K. Horie, and K. Hirano, Macromolecules, 22, 558 (1989). (c) E. F. Meyer, A. M. Jamieson, R. Simha, J. H. M. Paleman, H. C. Booiji, and F. H. Maurer, $J$. Polym. Sci., 31, 243 (1990).

9. R. Stetter and D. Zuchowska, J. Appl. Polym. Sci., 41, 595 (1990).

10. C. M. Roland and K. L. Ngai, Macromolecules, 24, 2261 (1992).

11. T. S. Chow, Macromolecules, 25, 440 (1992).

12. A. K. Chakraborty and P. M. Adriani, Macromolecules, 25, 2470 (1992).

13. (a) H. Kashiwabara, S. Shimada, Y. Hori, and M. Sakaguchi,
Adv. Polym. Sci., 82, 141 (1987). (b) S. Shimada, Prog. Polym. Sci., 17, 1045 (1992) and references in these articles.

14. S. Shimada, Y. Hori, and H. Kashiwabara, Macromolecules, 23 , 3709 (1990).

15. S. Shimada, Y. Hori, and H. Kashiwabara, Macromolecules, 25, 2771 (1992).

16. S. Shimada, Part I of this series. Polym. J., 28, 655 (1996).

17. P. Törmälä, H. Lattila, and J. J. Lindberg, Polymer, 14, 481 (1973).

18. C. Silvestre, S. Cimmino, E. Martuscelli, F. E. Karasze, and W. J. Macknight, Polymer, 28, 1190 (1987).

19. C. Marco, J. G. Fatou, M. A. Gomez, H. Tanaka, and A. E. Tonnelli, Macromolecules, 23, 2183 (1990).

20. "Polymer Handbook," Wiley-Interscience, New York, N.Y., 1979.

21. (a) E. Martuscelli, M. Pracella, and W. P. Yue, Polymer, 25, 1097 (1984). (b) M. L. Addonizio, E. Martuscelli, and C. Silverstre, Polymer, 28, 183 (1987). (c) E. Jhon, S. H. Jeon, and T. Ree, $J$. Polym. Sci., Lett. Ed., 27, 9 (1989). (d) E. Jhon and T. Ree, J. Polym. Sci., A, Polym. Chem. Ed., 28, 385 (1989).

22. C. Booth, C. J. Devoy, and G. Gel, Polymer, 12, 327 (1971).

23. S. Shimada, K. Kashima, Y. Hori, and H. Kashiwabara, Rep. Polym. Phys., Jpn., 32, 455 (1989). 